\title{
FACTORS INFLUENCING THE ADOPTION OF BUILDING INFORMATION MODELLING (BIM) IN THE SOUTH AFRICAN CONSTRUC- TION AND BUILT ENVIRONMENT (CBE) FROM A QUANTITY SURVEYING PERSPECTIVE
}

pages: $142-150$

\author{
Berco Venter Sams Pfukani Ngobeni \\ HENDRI DU PLESSIS
}

\begin{abstract}
A B S TR A C T
The construction industry has often been described as stagnant and out-of-date due to the lack of innovation and innovative work methods to improve the industry (WEF, 2016; Ostravik, 2015). The adoption of Building Information Modelling (BIM) within the construction industry has been relatively slow (Cao et al., 2017), particularly in the South African Construction and Built Environment (CBE) (Allen, Smallwood \& Emuze, 2012). The purpose of this study was to determine the critical factors influencing the adoption of BIM in the South African CBE, specifically from a quantity surveyor's perspective, including the practical implications. The study used a qualitative research approach grounded in a theoretical framework. A survey questionnaire was applied to correlate the interpretation of the theory with the data collected (Naoum, 2007). The study was limited to professionals within the South African CBE. The study highlighted that the slow adoption of BIM within the South African CBE was mainly due to a lack of incentives and subsequent lack of investment towards the BIM adoption. The study concluded that the South African CBE operated mainly in silos without centralised coordination. The BIM adoption was only organic. Project teams were mostly project orientated, seeking immediate solutions, and adopted the most appropriate technologies for the team's composition. The study implies that the South African CBE, particularly the Quantity Surveying profession, still depends heavily on other roleplayers in producing information-rich 3D models. Without a centralised effort, the South African Quantity Surveying professionals will continue to adopt BIM technology linearly to the demand-risk ratio as BIM maturity is realised in the South African CBE.
\end{abstract}

KEY WORDS

Building Information Modelling (BIM), South African Construction and Built

Environment (CBE), design silos

10.2478/emj-2021-0027
Hendri du Plessis

University of the Free State, South Africa ORCID 0000-0002-6342-0702

Corresponding author: e-mail: duplessishb@ufs.ac.za

Berco Venter

University of the Free State, South Africa

Sams Pfukani Ngobeni

University of the Free State, South Africa

\section{INTRODUCTION}

The construction industry is one of the biggest industries globally, with one of the most significant numbers of employees. The opposite is true about the industry when it comes to being innovative. The construction industry has often been described as stagnant and out of date due to the lack of innovative work methods to improve the industry. Although some new technologies have emerged in the industry's market, innovation and adoption of innovation

Venter, B., Ngobeni, S. P., \& du Plessis, H. (2021). Factors influencing the adoption of Building Information Modelling (BIM) in the South African Construction and Built Environment (CBE) from a quantity surveying perspective. Engineering Management in Production and Services, 13(3), 142-150. doi: 10.2478/emj-2021-0027 
in the sector are still low (WEF, 2018; Abubakar et al., 2014). This includes Building Information Modelling (BIM), Integrated Project Delivery (IPD), Integrated Design Processes (IDP) and Lean construction.

The adoption of Building Information Modelling (BIM) within the Construction Industry has been relatively slow (Cao et al., 2017), particularly in the South African Construction and Build Environment (CBE) (Allen, Smallwood \& Emuze, 2012).

BIM can be defined as a set of interacting tools, processes, and technologies guided by norms and rules to support practitioners in the construction environment developing a building project (Eastman et al., 2011; Al Safarini et al., 2021). BIM can be extremely beneficial to construction companies willing to devote the time and finances required to adopt BIM fully. It is meant to ease the collaboration process between the different stakeholders. BIM is the collaboration tool that makes it possible to bring all different construction disciplines together into one single authoritative project model. It is also beneficial to the Quantity Surveyor as a valuable measurement and quantification tool that makes the project more transparent and enhances project efficiency (ASAQS, 2017).

Even though BIM has the potential to benefit the South African CBE and, particularly, the Quantity Surveyor, numerous factors still affect the adoption of BIM in South Africa by QS firms. Therefore, its adoption is still very slow (Allen, Smallwood \& Emuze, 2012). The purpose of this study was to determine the critical factors influencing the adoption of BIM in the South African CBE from a Quantity Surveyor's perspective. This research endeavoured to highlight the aspects that can be addressed or focussed on by BIM users in the industry. The study's objective was to determine the present level of awareness, industry readiness, the current rate of use and the perception of Quantity Surveyors regarding the adoption of BIM in the CBE.

The study aimed to establish the current and most pressing challenges causing the South African CBE's seemingly slow adoption of BIM from a Quantity Surveyor's perspective. This was accomplished by measuring the health of the industry against the BIM maturity model (Sacks et al., 2018) and by comparing two data collection sets. One endeavoured to establish the common challenges towards BIM adoption, while the second investigated the relationship between company size and BIM adoption.

The study mainly focused on the South African CBE from a Quantity Surveyor's perspective.

\section{LITERATURE REVIEW}

\subsection{QUANTITY SURVEYOR}

The Quantity Surveyor (QS) is seen as the financial and development consultant that provides advice to either clients or contractors on contractual arrangements and cost advice. The QS is allowed to prepare contractual documentation for the project and also perform cost planning and cost management throughout the project to ensure that the development stays within the budget. According to the Quantity Surveyors' Act of 2000, anyone who wants to become a qualified QS in South Africa needs the necessary qualifications and experience and need to register with the South African Council of Quantity Surveyors (SACQSP) before being allowed to provide services to the public (Maritz \& Siglé, 2016).

According to the Royal Institute for Charted Surveyors (RICS, 2007), some of the traditional QS functions include:

- Preparing the budget by determining the client's requirements and using estimates.

- Preparing feasibility studies of the proposed project.

- Preparing the Bills of Quantities used to obtain the best possible tenders from numerous possible contractors.

- Preparing contractual documentation.

- Monitoring costs while providing reports to clients throughout the project.

- Determining the Final Account of the project.

Larsen (in Ostravik, 2015) concludes that technology adoption diffuses firms and individuals, mainly from project to project. His Innovation Diffusional Network highlights two main parameters: broader institutional forces and peer pressure. These parameters further incorporate industry parameters, namely, negotiation space, contextual thresholds, group thinking, power available, selective exposure, actor thresholds, and the notion of needs. These parameters aptly explain how the BIM adoption is currently taking place. This complex, innovative diffusion can further be divided into two levels: diffusion among firms and diffusion among individuals within a firm.

The functions that a QS provides to the client or contractor are extremely time-consuming and might contain errors due to incorrect quantity take-offs for projects with large numbers of drawings (Mayouf, Gerges \& Cox, 2019). When variations or changes 


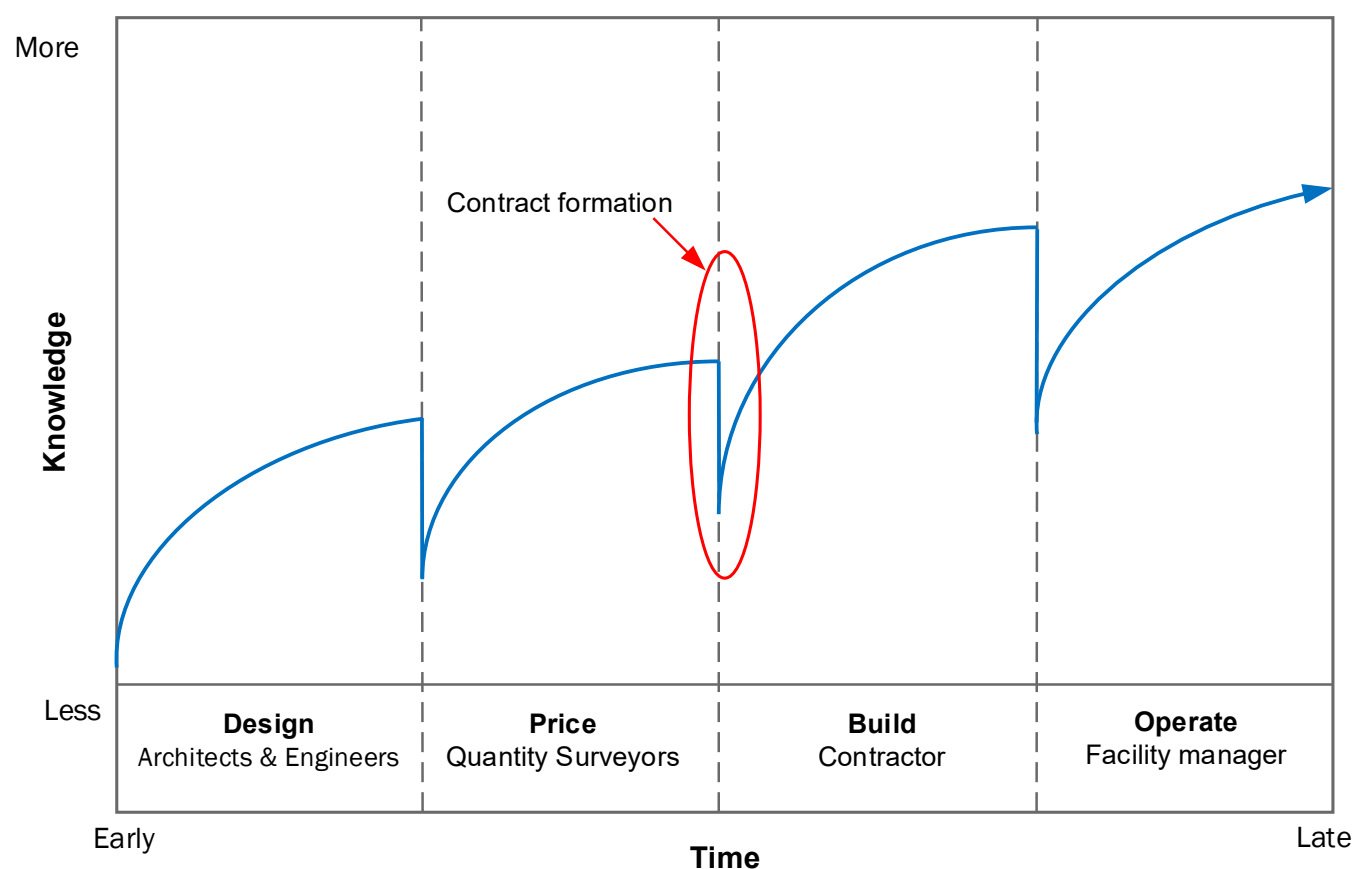

Fig. 1. Traditional method of information flow from one process to the other Source: (Bernstein, 2015, video, cited du Plessis, 2019. p. 125).

occur in the traditional "manual" processes, it is time-consuming to correct and often leads to inaccurate estimates (RICS, 2013). It is essential to note that the quality of the drawings will also have a major impact on the accuracy of the estimates (Sacks et al., 2018; Exactal, 2018). Inaccurate drawings are among the biggest challenges faced by the QS. Subsequently, this highlights the importance of the QS to be a part of the design stage as early as possible, to collaborate with the designers and minimise errors. The understanding of the scope and the feedback to other consultants are crucial for proper Integrated Project Management of a construction project (Du Plessis \& Oosthuizen, 2018).

To summarise, the design consultants continually produce more information, which the QS has to interpret to compile the procurement documents. This summary is depicted in Fig. 1.

Fig. 1 clearly shows that information is continually lost as it is passed to the next role player. This emphasises the benefit of BIM, which is further discussed in the next section.

1.2. Building Information Modelling (BIM)

Allen, Smallwood and Emuze (2012) claim that by offering a platform that makes it easier to handle, identify and avoid conflicts in project designs, BIM offers potential benefits to architects during the design phase of a construction project. They further claim that projects would benefit from this system as the cost of rework due to design flaws and disputes will be drastically lower or non-existent. Uysal (in Kocakaya, Namli \& Isikdag, 2019) claims that the on-site use of BIM in construction projects offers visual and appropriate information to contractors, which is obtained on-site at a reasonable time. Consequently, there is a likelihood of reducing the number of requests for information (RFI), disputes, and conflicts frequently found on construction sites.

The construction industry has fallen victim numerous times to being labelled as inefficient with low productivity levels. Due to this recurring problem, an effort has been made to provide new techniques and technologies to improve the productivity levels, enhance the quality of work and reduce the overall construction costs throughout the project. An innovative technology that is believed to be a step in the right direction for the construction industry is BIM (Panuwatwanich, 2013).

The BIM maturity levels currently range from level 0 to 3 (four levels). BIM maturity levels are defined according to criteria with which BIM users are required to comply (to be BIM-compliant). At levels 0 and 1, there is a lack of BIM use, or other systems are being overused (Sacks et al., 2018). In April 2016, the UK Government mandated that any public sector's construction project had to comply with BIM level 2. Level 2 requires structured data for a built asset that provides collaboration throughout 
the supply chain. Level 3 will be targeted once the entire construction industry has managed to comply with level 2 (Malleson, 2018).

Integrating the cost element into BIM creates the fifth dimension (5D) (4D BIM refers to scheduling and $6 \mathrm{D}$ refers to facilities management). This is seen as a step in the right direction to improve cost management by many competitive firms (Smith, 2016). According to Smith (2016), BIM allows the Quantity Surveyor more time to provide cost advice and cost knowledge to the project team because the time to produce estimates, quantity take-offs, bills of quantities and other time-consuming data is greatly reduced. 5D BIM enables the QS to perform functions, such as quantity take-offs, measuring directly from a 5D BIM model that is linked to estimating software that automatically updates when changes occur (Haque \& Mishra, 2007).

The United Kingdom (UK), Ireland and New Zealand are examples of governments taking a leading role in the BIM implementation. Since April 2016, the UK has implemented a mandate that requires all projects funded by the central government to be on the BIM maturity level 2. The National BIM Report (Waterhouse, 2019) states that BIM awareness and adoption levels had increased from $10 \%$ in 2011 to 70 $\%$ in 2019. In Ireland, the National BIM Report state that, from the 116 respondents in their research, $76 \%$ have adopted BIM in their work environment. According to the BIM Acceleration Committee (Waterhouse, 2019), New Zealand has experienced a total growth rate of only $4 \%$ in four years as it grew from $55 \%$ in 2016 to $59 \%$ in 2019. Although these countries are deemed as countries leading in the BIM adoption, there are still numerous barriers influencing the adoption of BIM in the UK and Ireland.

The South African CBE are years behind other countries with multiple and largely fragmented industries. Many QS companies are small, two to three-man practices, with diverse spectra of clients and types of projects. Clients also vary by financial strengths and the type of projects. This leads to different technological requirements and project team compositions.

The South Africa CBE should show improvement in the entire value chain of the Project Life Cycle (PLC) in an effort to create a market for those producing usable data (Potgieter, 2017). The BIM Institute, in conjunction with the ASAQS, have taken the initiative to compile an Elemental Classification System to assist model developers in producing such information for the Quantity Surveyor, who, in turn, can convey it to the contractors. The objective is to standardise the way BIM information is classified within the model (ASAQS, 2018). This correlates with the suggestion of better collaboration between the supply chain and stakeholders (Odubiyi et al., 2019). Waiting for the South African Government will not promote the BIM implementation (Potgieter, 2017), and the BIM adoption will be driven by other stakeholders in an organic manner.

As a result of the COVID-19 pandemic, the South African CBE has experienced an additional economic decline over and above the one of 2016 (South Africa, 2021). This, together with the factors mentioned above, led to the provisional conclusion that the South African CBE is currently adopting BIM in an organic manner to address each project's demands in a way most suitable for compiling the project team with each organisation meeting the minimum requirements on an ad hoc basis.

\section{RESEARCH METHODS}

Two research data sets were used in an endeavour to answer the main research question. Two separate data sampling questionnaires were used to enable exploration and placement of the current state of the South African CBE in relation to the BIM maturity model.

A qualitative method was used on this project, placing the interpretation of theory on the data collected. A survey approach was used for data gathering purposes (Naoum, 2007), with a total of 61 professionals participating in the survey.

The two surveys were divided into the following data collection themes:

1. Factors influencing the adoption of BIM in the South African CBE.

2. The connection between organisational size and the adoption of BIM in the South African CBE.

For this study, a non-probability sampling design was used to determine the sample. This sampling process does not provide an equal chance for respondents to be selected within the population as it makes use of subjective methods to select which respondents or individuals will be forming part of the sample (Trobia, 2008). The sampling method of this study was convenience sampling. Convenience sampling is a sampling technique of non-probability sampling where respondents are selected based on the convenience of their nearness and accessibility to the researcher (Leedy \& Ormond, 2010). 
Tab.1. Background of respondent firms and BIM implementation

\begin{tabular}{|l|r|l|r|c|r|l|r|r|}
\hline \multicolumn{2}{|c|}{ LOCATION OF WORK } & \multicolumn{2}{c|}{ VALUE OF WORK } & \multicolumn{2}{c|}{ BIM USAGE } & \multicolumn{2}{c|}{ ORGANISATIONAL SIZE } \\
\hline Local and international projects & $41 \%$ & Below R20mil & $32 \%$ & Full use & $0 \%$ & Micro: 0-10 & 13 \\
\hline International projects only & $6 \%$ & R20mil to R100mil & $32 \%$ & Partial use & $47 \%$ & Small: $11-50$ & 9 \\
\hline Local projects only & $53 \%$ & Above R 100mil & $35 \%$ & Not at all & $53 \%$ & Medium: $51-250$ & 9 \\
\hline
\end{tabular}

Tab. 2. Identification of barriers in the South African CBE adoption of BIM

\begin{tabular}{|c|c|c|c|c|c|c|}
\hline & $\begin{array}{l}\text { STRONGLY } \\
\text { DISAGREE } \\
\quad(1)\end{array}$ & $\begin{array}{l}\text { SOMEWHAT } \\
\text { DISAGREE } \\
\text { (2) }\end{array}$ & $\begin{array}{l}\text { SOMEWHAT } \\
\text { AGREE (3) }\end{array}$ & AgreE (4) & $\begin{array}{l}\text { STRONGLY } \\
\text { AGREE (5) }\end{array}$ & MEAN \\
\hline $\begin{array}{l}\text { Is there a lack of incentive to adopt in the } \\
\text { South African CBE }\end{array}$ & $0 \%$ & $0 \%$ & $15 \%$ & $29 \%$ & $56 \%$ & 10.0 \\
\hline Is there a lack of client demand & $0 \%$ & $3 \%$ & $15 \%$ & $50 \%$ & $32 \%$ & 9.3 \\
\hline Is BIM worth it & $2 \%$ & $3 \%$ & $18 \%$ & $62 \%$ & $15 \%$ & 8.7 \\
\hline Will BIM improve the accuracy of estimates & $0 \%$ & $9 \%$ & $21 \%$ & $46 \%$ & $24 \%$ & 8.7 \\
\hline $\begin{array}{l}\text { Will BIM improve communication between } \\
\text { stakeholders }\end{array}$ & $6 \%$ & $3 \%$ & $29 \%$ & $44 \%$ & $18 \%$ & 8.3 \\
\hline $\begin{array}{l}\text { Will BIM enhance the efficiency of the con- } \\
\text { struction process and reducing construction } \\
\text { costs? }\end{array}$ & $12 \%$ & $6 \%$ & $26 \%$ & $47 \%$ & $9 \%$ & 7.6 \\
\hline Is BIM understandable & $6 \%$ & $12 \%$ & $47 \%$ & $32 \%$ & $3 \%$ & 7.1 \\
\hline Is the current 2D software good enough & $9 \%$ & $24 \%$ & $35 \%$ & $29 \%$ & $3 \%$ & 6.6 \\
\hline
\end{tabular}

The study incorporated primary data collected through the process explained above, together with the secondary data (Naoum, 2007) collected by reviewing the literature to reach a conclusion. The research furthermore went through an ethical clearance process at the University of the Free State.

\section{RESEARCH RESULTS}

\subsection{FACTORS INFLUENCING THE ADOPTION OF BIM in the South African CBE}

The first study used a qualitative questionnaire that was distributed among Quantity Surveying firms in South Africa. The objective was to establish a baseline for the barriers to adopting BIM by Quantity Surveyors and the possible link between the organisation and/or project size. Table 1 illustrates the background of these firms on location, value, BIM implementation, and the size of their organisation.

A relationship may be observed between the monitory value of projects and the adoption of BIM. It does, however, indicate that none of the firms that responded had fully adopted BIM. Thus, without a centralised effort, BIM is being adopted systematically through the BIM maturity levels. A clearer data- set would be required to evaluate the current state of BIM maturity in the South African CBE. Table 2 illustrates the respondents' perceptions of BIM barriers in the South African CBE, ranked according to the barriers (the relevant factors shown in the appropriate headings).

Table 2 indicates that most respondents are eagerly waiting for BIM collaboration and are exploring the possible benefits of BIM adoption. Most respondents see the use of BIM-compatible software as a means to improve the accuracy and efficiency of measurement work; however, they are currently using what is required to get the job done.

Because the first study provided limited answers on BIM adoption and maturity levels of the South African $\mathrm{CBE}$ and, in particular, from a QS perspective, the subsequent study attempted to address this shortfall.

\subsection{CONNECTION BETWEEN ORGANISATIONAL SIZE AND THE ADOPTION OF BIM IN THE South African CBE}

The study sought to find clarity from the greater South African CBE and wanted to establish a connection between the size of the organisation and the adoption of BIM. Again, a qualitative questionnaire was used to gather data from Project Managers, 
Architects, Quantity Surveyors, Engineers and Contractors.

Table 3 illustrates the findings of the data collection process, in which the respondents had to indicate their agreement, neutrality or disagreement with the statements. The means of the questionnaire were subsequently calculated, as shown in Table 3 .
A standard t-test was done against the standard deviation of the different organisation sizes and the barriers to establish the relevance of the data. The $t$-test revealed that a significant trend occurred between large organisations and other organisation sizes. However, a very low significance was observed between the micro- to medium-sized organisations (Table 4).

Tab. 3. BIM adoption barriers compared to organisational size ( $D=$ Disagree; $N=$ Neutral; $A=$ agree)

\begin{tabular}{|c|c|c|c|c|c|c|}
\hline \multicolumn{7}{|c|}{ BIM ADOPTION BARRIERS } \\
\hline \multirow{2}{*}{\multicolumn{3}{|c|}{ DISAGREE (1); NEUTRAL (2); AGREE (3) }} & \multicolumn{4}{|c|}{ ORGANISATION SIZE } \\
\hline & & & \multirow{2}{*}{$\begin{array}{l}\begin{array}{c}\text { MICRO: } \\
\text { 0-10 }\end{array} \\
2.4\end{array}$} & \multirow{2}{*}{$\begin{array}{r}\begin{array}{r}\text { SMALL: } \\
11-50\end{array} \\
2.9\end{array}$} & \multirow{2}{*}{$\begin{array}{r}\text { MEDIUM: } \\
\mathbf{5 1 - 2 5 0} \\
2.6\end{array}$} & \multirow{2}{*}{$\begin{array}{l}\begin{array}{l}\text { LARGE: } \\
250 \\
\text { \& ABOVE }\end{array} \\
1.7\end{array}$} \\
\hline \multirow{8}{*}{ 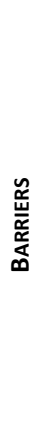 } & 1 & Cost of additional resources & & & & \\
\hline & 2 & Increased level of risk and liability & 2.6 & 2.4 & 1.7 & 1.4 \\
\hline & 3 & Current policies for procurement methods and procedures & 2.6 & 2.8 & 1.9 & 2.0 \\
\hline & 4 & Lack of comprehensive frame or implementation plan & 2.4 & 3.0 & 2.4 & 1.7 \\
\hline & 5 & Lack of skills and training & 2.6 & 3.0 & 2.9 & 1.6 \\
\hline & 6 & $\begin{array}{l}\text { Organizational structure and culture challenges (lack of } \\
\text { organization support) }\end{array}$ & 2.8 & 2.1 & 2.6 & 2.1 \\
\hline & 7 & Lack of demand by clients & 2.6 & 2.6 & 2.6 & 2.0 \\
\hline & 8 & Lack of BIM awareness & 2.6 & 2.6 & 2.6 & 2.0 \\
\hline
\end{tabular}

Tab. 4. T-test between barriers and different organisation data sets

\begin{tabular}{|c|c|c|c|c|c|c|c|c|}
\hline \multirow{4}{*}{ 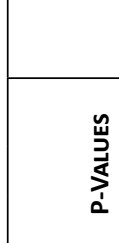 } & \multicolumn{2}{|c|}{$\begin{array}{c}\text { A) MICRO AGAINST } \\
\text { OTHER }\end{array}$} & \multicolumn{2}{|c|}{$\begin{array}{c}\text { B) SMALL AGAINST } \\
\text { OTHER }\end{array}$} & \multicolumn{2}{|c|}{$\begin{array}{c}\text { C) MEDIUM AGAINST } \\
\text { OTHER }\end{array}$} & \multicolumn{2}{|c|}{$\begin{array}{l}\text { D) LARGE AGAINST } \\
\text { OTHER }\end{array}$} \\
\hline & a) \& b) & 0.43 & b) \& a) & 0.43 & c) \& a) & 0.31 & d) \& a) & 0.00001 \\
\hline & a) \& c) & 0.31 & b) \& c) & 0.17 & c) \& b) & 0.17 & d) \& b) & 0.00004 \\
\hline & a) \& d) & 0.00001 & c) \& d) & 0.00004 & c) \& d) & 0.004 & d) \& c) & 0.004 \\
\hline LEGEND & & \multicolumn{2}{|c|}{ Non-significant } & & \multicolumn{2}{|c|}{ Strongly significant } & & \\
\hline
\end{tabular}

\section{BIM ADOPTION DETERANT FACTORS/BARRIERS}

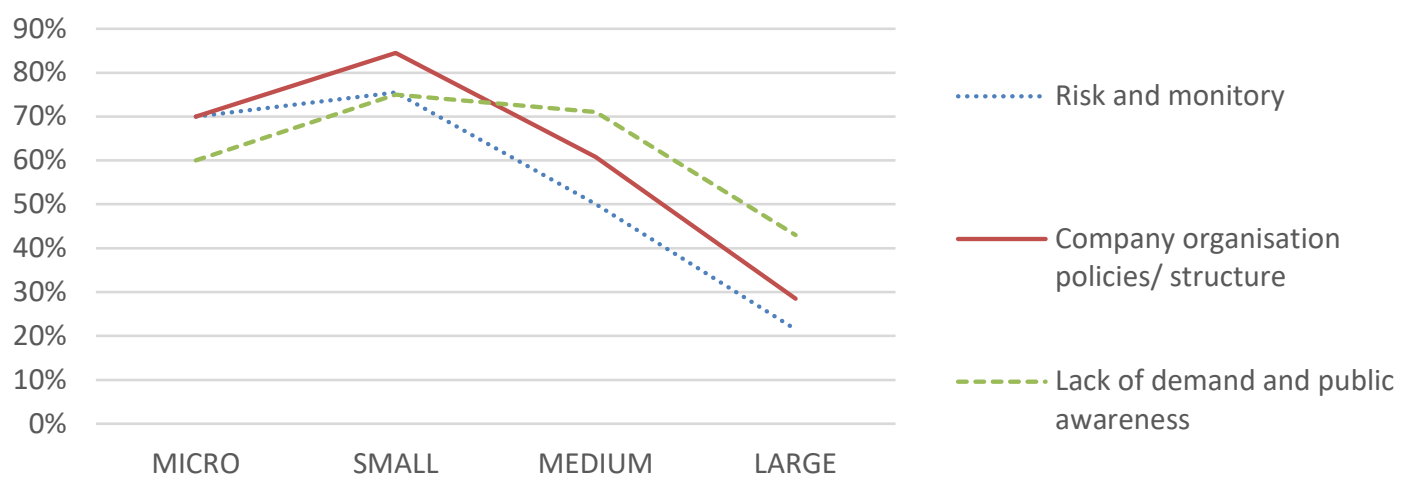

Fig. 2. Grouped barriers to BIM adoption [\%] 
The data is further grouped into three basic categories to enhance the placement theory discussion. The grouping allowed for a graphical representation of the percentage of the respondents that agreed with the statements, according to their organisational size:

From the second data set, a clearer perspective is provided on the organisations' size and uptake and/or positioning towards the BIM implementation. Fig. 2 shows a clear tendency for the larger firms to adopt BIM differently and different perceptions towards the barriers than smaller firms. An average of $70 \%$ of micro firms and $76 \%$ of small firms indicated that cost and risk are barriers for their company. In comparison, $70 \%$ of medium-sized firms indicated that cost is a challenge, and only $29 \%$ noted that it carried significant risk. Micro to medium-sized firms said that client demand and BIM awareness (60\% to $71 \%$ agreement) were barriers to overcome, while only 43 $\%$ of large firms agreed with this statement.

\section{DISCUSSION OF THE RESULTS}

The summarised criteria of barriers (risk and monetary; company organisational structure/policies and lack of demand) indicate that the larger firms experienced these barriers to BIM adoption differently than micro to medium-sized companies. Larger firms may be exposed to larger clients and/or more technical projects, putting them in a better position to invest in these technologies. These firms also conduct more international work, which may explain this perception. Smaller firms have different objectives than larger firms with different business models.

The conclusion from the above information is that the larger firms are more exposed to BIM because of a greater client/peer demand and, subsequently, the company's policies and associated risk towards monetary expenses. However, the micro and small firm comparison of risk/financial barriers is interesting. This might be explained by micro-enterprises considering BIM adoption more viable than small firms because of saving overhead costs. For these firms, the cost of appointing additional staff to grow the business might be offset by the cost/risk of empowering existing staff, acquiring BIM technology, and adopting these skills and services for clients.

Many large companies have different in-house services that promote greater collaboration between the project team members, leading to greater problem-solving abilities on projects. This, in turn, promotes a fundamentally different outlook towards BIM adoption.

\section{CONCLUSIONS}

The information from the literature, namely, that the majority of QS firms are micro-organisations, confirms the first data set's conclusion that QS firms are investigating BIM adoption; however, they are not compelled to do so because of demand. QS firms realise the potential of what BIM might provide in more efficient 5D BIM take-offs (measurements). However, facility managers and contractors depend on other consultants to provide the necessary information.

The literature indicated that BIM adoption follows the maturity levels. The South African CBE is no exception, showing similar trends to other countries. However, in South Africa, it is primarily driven by the private construction industry and not the Government. The subsequent result is that BIM is adopted by means of supply and demand or organically. The South African CBE maturity can currently be rated as BIM level 1, with the QS not benefiting from current models produced.

The research data also indicates that technology diffusion is currently taking place, with larger, more resourced companies taking the lead. However, the data shows that as $3 \mathrm{D}$ model production becomes more proficient throughout the differently sized organisations, the $4 \mathrm{D}$ to $6 \mathrm{D}$ producers will also become convergent.

With associations and councils working on solutions by producing quality standards through collaboration and learning from other countries, the South African CBE industry will gradually progress in BIM adoption. This, however, takes time, and without a more centralised drive by the Government, the adoption of BIM will still take place organically.

By addressing current challenges professionally, the industry is addressing future challenges by focusing on improving efficiency. Further research is required into a possible improvement of collaboration in the industry. Subsequently, the following suggestions are made from the study:

- The project team requires greater collaboration by focusing on the information needs of the dependent parties. The Elemental Classification System developed by the ASAQS in conjunction with the BIM Institute and the South African Institute of Architecture (SAIA) is a great start.

- Implement BIM into the curriculum of educational facilities and provide in-house training to increase the knowledge and skills of current professionals. 
- Clients should be educated to gain more knowledge with regards to how BIM can benefit them.

- The Government should follow in the footsteps of BIM-leading countries by implementing BIM mandates and standards that require companies to meet certain BIM criteria for them to take part in government projects.

\section{ACKNOWLEDGEMENTS}

The publication of the article for 11th International Conference on Engineering, Project, and Production Management - EPPM2021 was financed in the framework of the contract no. DNK/ SN/465770/2020 by the Ministry of Science and Higher Education within the "Excellent Science" programme.

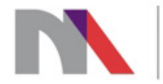

Ministry of Science

and Higher Education

Republic of Poland

\section{LITERATURE}

Abubakar, M., Ibrahim, Y. M., Kado, D., \& Bala, K. (2014). Contractors Perception of the Factors Affecting Building Information Modelling (BIM) Adoption in the Nigerian Construction Industry. Computing in Civil and Building Engineering, 167-178.

Al Safarini, N., Hasan, A., Sakhrieh, A., Alnahhal, M., \& Al Hazza, M. (2021). Crucial Role of Efficient Communication on Construction Projects Progress, Deliverablesand Conflicts Reduction in the United Arab Emirates. Polish Journal of Management Studies, 23(1), 9-22.

Allen, C., Smallwood, J., \& Emuze, F. (2012). Building Information Modelling: South African architect's and contractor's perceptions and practices. South Africa: Nelson Mandela Metropolitan University.

ASAQS - The South African Association of Quantity Surveying (2018). Announcing the ASAQS Elemental Class system. Retrieved from https://www.asaqs. co.za/news/395452/Announcing-the-ASAQS-Elemental-Class-system.htm

Bernstein, P. (2015). TEDx Talks. The Future of Making Buildings. Retrieved from https://www.youtube.com/ watch?v=Kg0gbG1DAkk

Cao, D., Li, H., Wang, G., \& Huang, T. (2017). Identifying and contextualising the motivations for BIM implementation in construction projects: An empirical study in China. International Journal of Project Management, 35(4), 658-669.

Du Plessis, H. B. (2019). Facilitation of construction project management through building contracts: A South African perspective on the locally developed suites of contracts. Acta Structilia, 26(1), 120147. doi: $10.18820 / 24150487 /$ as26i1.5
Du Plessis, H. B., \& Oosthuizen, P. M. (2018). Construction project management through building contracts, a South African perspective. Acta Structilia, 25(1), 152181. doi: $10.18820 / 24150487 /$ as25i1.6

Eastman, Ch., Teicholz, P., Sacks, R., \& Liston, K. (2011). BIM handbook, a guide to building information modelling for owners, designers, engineers, contractors, and facility Managers. 2nd ed. John Wiley \& Sons.

Exactal (2018). Digital Drawing File Optimisation. For Measurement \& Estimating Purposes Simple tips for a collaborative approach to improved drawing file intelligence. CostX6.7 Exactal Technologies Pty Ltd.

Haque, M. E., \& Mishra, R. (2007). 5D virtual construction: Designer/constructors perspective'. In 10th International Conference on Computer and Information Technology, 1-4.

Kocakaya, M. N., Namli, E., \& Isikdag, U. (2019). Building Information Management (BIM). A new approach to Project Management. Journal of Sustainable Construction Materials and Technologies, 4(1), 323332.

Leedy, P. D., \& Ormond, J. E. (2010). Practical research, planning and design. 11th ed. Malaysia: Pearson Education Limited.

Malleson, A. (2018). The National BIM Report 2018. National Building Specification (NBS). RIBA Enterprises Ltd. Retrieved from https://www.thenbs.com/ knowledge/the-national-bim-report-2018

Maritz, M. J., \& Siglé, H. M. (2016). Quantity surveying in South Africa. Pretoria: Construction Economics Associates (Pty) Ltd.

Mayouf, M., Gerges, M., \& Cox, S. (2019). 5D BIM: an investigation into the integration of quantity surveyors within the BIM process. Journal of Engineering Design and Technology, 17(3), 537-553.

Naoum, S. G. (2007). Dissertation Research \& Writing for Construction Students. 2nd ed. Elsevier Ltd.

Odubiyi, T. B., Aigbavboa1, C., Thwala, W., \& Netshidane N. (2019). Strategies for building information modelling adoption in the South African construction industry. Conference. Modular and Offsite Construction (May 21 -24). Banff Springs, Canada.

Ostravik, F. (2015). Incentives for innovation in construction. In F. Ostravik, A. Dainty C. \& Abbott (Eds.), Construction Innovation (pp. 13-28). United Kingdom: Wiley Balckwell.

Panuwatwanich, K., Wong, M. L., Stewart, R. A., \& Mccarthy, T. J. (2013). Integrating building information modelling (BIM) into engineering education: an exploratory study of industry perceptions using social network data Publication Details. Retrieved from http://ro.uow.edu.au/eispapers/1920

Potgieter, P. (2017). The conflicted state of BIM in South Africa. Retrieved from http://www.ee.co.za/article/ conflicted-state-bim-south-africa.html

RICS - Royal Institute of Chartered Surveyors (2007). Quantity surveyor services. Royal Institute of Chartered Surveyors. Retrieved from https://www.rics. org/globalassets/rics-website/media/upholding-professional-standards/sector-standards/construction/ quantity-surveyor-services-rics.pdf 
RICS - Royal Institute of Chartered Surveyors (2013). Design and specification. RICS Professional Guidance, UK. London, UK: RICS.

Sacks, R., Eastman C., Lee G., \& Teicholz, P. (2018). BIM handbook, a guide to building information modeling for owners, designers, engineers, contractors, and facility Managers. 3rd ed. Hoboken, NJ: Wiley.

Smith, P. (2016). Project Cost Management with 5D BIM. Procedia - Social and Behavioural Sciences, 226, 193 200.

South Africa (2021). Statistics South Africa. Statistical Release P0441, Gross domestic product. 8 June 2021. Retrieved from http://www.statssa.gov.za/publications/P0441/P04411stQuarter2021.pdf

The Association of South African Quantity Surveyors (2017). The conflicted state of BIM in South Africa. Retrieved from https://www.asaqs.co.za/ news/348631/The-conflicted-state-of-BIM-inSouth-Africa.htm? page=SalarySurveyReport

Trobia, A. (2008). Nonprobability sampling. In P. J. Lavrakas (Ed.), Encyclopedia of survey research methods (pp. 784-785). Thousand Oaks, CA: Sage Publications, Inc.

Waterhouse, R. (2019). The National BIM Report 2019. National Building Specification (NBS). RIBA Enterprises Ltd. Retrieved from https://www.thenbs.com/ knowledge/national-bim-report-2019

WEF - World Economic Forum (2018). The Fourth Industrial Revolution is about to hit the construction industry. Here's how it can thrive. Retrieved from https://www.weforum.org/agenda/2018/06/ construction-industry-future-scenarios-labourtechnology/ 